\title{
Taxonomia e distribuição do gênero Caulerpa Lamouroux (Bryopsidales - Chlorophyta) na costa de Pernambuco e Arquipélago de Fernando de Noronha, Brasil
}

\author{
Suellen Brayner ${ }^{1,3}$, Sonia Maria Barreto Pereira ${ }^{1,2}$ e Maria Elizabeth Bandeira-Pedrosa ${ }^{2}$
}

Recebido em 22/03/2006. Aceito em 18/12/2007

\begin{abstract}
RESUMO - (Taxonomia e distribuição do gênero Caulerpa Lamouroux (Bryopsidales - Chlorophyta) na costa de Pernambuco e Arquipélago de Fernando de Noronha, Brasil). Este trabalho identifica e fornece a distribuição do gênero Caulerpa na costa de Pernambuco $\left(07^{\circ} 30^{\prime} \mathrm{S}\right.$ e $\left.09^{\circ} 00^{\prime} \mathrm{W}\right)$ e no Arquipélago de Fernando de Noronha (03⒌ $1^{\prime} \mathrm{S}$ e $\left.32^{\circ} 25^{\prime} \mathrm{W}\right)$. As coletas foram realizadas em 32 praias da costa de Pernambuco no período entre abril/2004 a novembro/2005, na região entre-marés. Em Fernando de Noronha as coletas foram feitas em junho/2006, na região entre marés e no infralitoral (10, 15 e $21 \mathrm{~m}$ de profundidade), em oito praias. Foram, também, analisadas as exsicatas de Caulerpa depositadas no Herbário Professor Vasconcelos Sobrinho (PEUFR) da Universidade Federal Rural de Pernambuco. Os resultados mostram que o gênero Caulerpa está representado na costa de Pernambuco, por 19 táxons infragenéricos. Algumas espécies apresentaram distribuição restrita como C. kempfii Joly \& Pereira, C. lanuginosa J. Agardh e C. serrulata (Forssk.) J. Agardh. Para o Arquipélago de Fernando de Noronha foram registrados três táxons infragenéricos.
\end{abstract}

Palavras-chave: algas marinhas, Brasil, Caulerpa, levantamento florístico, Nordeste

\begin{abstract}
Taxonomy and distribution of the genus Caulerpa Lamouroux (Bryopsidales - Chlorophyta) on the coast of Pernambuco State and Fernando de Noronha Archipelago, Brazil). This paper analyzes the taxonomy and distribution of the genus Caulerpa on the coast of Pernambuco ( $07^{\circ} 30^{\prime} \mathrm{S}$; 0900'W) and in the Fernando de Noronha Archipelago (03 $51^{\circ}$ 'S; $32^{\circ} 25^{\prime}$ W). Sampling was carried out on the coast of Pernambuco from April/2004 to November/2005, in the intertidal zone of 32 beaches. On Fernando de Noronha collections were made in June/2006 in the intertidal and infralittoral (10,15 and 21m depth) regions of eight beaches. Exsiccata of Caulerpa from the Professor Vasconcelos Sobrinho Herbarium (PEUFR) were also examined. The results showed that the genus Caulerpa is represented on the coast of Pernambuco state by 19 infrageneric taxa. Some species had restricted distributions such as $C$. kempfii Joly \& Pereira, C. lanuginosa J. Agardh and C. serrulata (Forssk.) J. Agardh. Three infrageneric taxa were registered for the Fernando de Noronha Archipelago.
\end{abstract}

Key words: seaweeds, Brazil, Caulerpa, floristic survey, Northeast

\section{Introdução}

O gênero Caulerpa Lamouroux foi reconhecido por Lamouroux em 1809. Cinco das oito espécies incluídas neste gênero tinham sido descritas previamente como pertencentes ao gênero Fucus por Forsskaal (1775). Em 1830, Greville estabelece uma ordem própria para Caulerpa Lamouroux designada "Caulerpeae". Kützing (1843), entretanto, não reconhece a ordem estabelecida por Greville e inclui seus representantes na ordem Eremospermae, subordem Coeloblastae. Harvey (1858) reconhece a ordem Siphonales (como Siphonaceae) com as subordens Caulerpeae e Codieae, a primeira abrangendo o gênero Caulerpa. De Toni (1889) reconhece, entre outras, a família Caulerpaceae, com os gêneros Caulerpa e Chlorodictyon (este com dúvidas pelo autor) entre as algas sifonadas na ordem Siphoneae. Blackman \& Tansley (1902) definem a terminação correta para esta ordem, passando a denominar Siphonales. Durante muitos anos a família Caulerpaceae foi incluída na ordem Siphonales até que Feldmam (1946), baseando-se na morfologia das plantas e da parede celular divide as Siphonales em Caulerpales e Eusiphonales. A primeira considerada como heteroplástica (com dois tipos de plastos, um fotossintético e outro um leucoplasto), incluindo as famílias Caulerpaceae, Udoteaceae e Dichotomosiphonaceae. A segunda com um único tipo de plasto, que é o cloroplasto, com as famílias

\footnotetext{
1 Universidade Federal Rural de Pernambuco, Programa de Pós-Graduação em Botânica, Rua Dom Manoel de Medeiros s.n., Dois Irmãos, 52171-900 Recife, PE, Brasil

2 Universidade Federal Rural de Pernambuco, Departamento de Biologia, Rua Dom Manoel de Medeiros s.n., Dois Irmãos, 52171-900 Recife, PE, Brasil

3 Autor para correspondência: subrayner@gmail.com
} 
Halicystidaceae, Bryopsidaceae, Derbesiaceae e Codiaceae. No entanto muitos autores não aceitaram esta classificação, colocando Caulerpaceae na ordem Siphonales (Papenfuss 1955; Smith 1955; Taylor 1960). Os trabalhos mais recentes consideram Caulerpaceae como membro de Bryopsidales (Oliveira et al. 2005; De Clerk et al. 2005; Wynne 2005). A referida família abriga, atualmente, os gêneros Caulerpa e Caulerpella Prud'homme \& Lokhorst (Wynne 2005).

As evidências experimentais demonstram que a morfologia dos ramos eretos do gênero Caulerpa Lamouroux apresenta grande plasticidade, podendo variar dentro da mesma espécie dependendo das condições ambientais (Ohba \& Enomoto 1987). Este fato levou alguns pesquisadores a descrever diferentes variedades e forma de uma espécie, muitas vezes de maneira equivocada (Oliveira et al. 2005).

Para o gênero Caulerpa, alguns autores como Graham \& Wilcox (2000) referem-se a 70 espécies, enquanto que outros como Dumay et al. (2002) a 100 espécies. O gênero encontra-se distribuído principalmente, nos mares tropicais. No Brasil, Caulerpa está representado por 38 táxons (Oliveira Filho 1977). No litoral de Pernambuco e Arquipélago de Fernando de Noronha foram referidas, até o momento, 33 táxons infragenéricos correspondendo a 17 espécies, sete variedades e nove formas (Pereira et al. 2002; Oliveira-Carvalho et al. 2003; Villaça et al. 2006). Esses dados estão baseados, principalmente, em trabalhos gerais de levantamento florístico, descrição de novas espécies e material depositado nos principais herbários nacionais.

Em virtude da representatividade do gênero, há necessidade de maiores informações taxonômicas e ecológicas que só serão possíveis através de um inventário a ele direcionado. Desta forma, este trabalho tem como objetivo realizar o levantamento florístico do gênero Caulerpa na costa de Pernambuco e Arquipélago de Fernando de Noronha fornecendo informações sobre sua taxonomia, distribuição e aspectos ecológicos.

\section{Material e métodos}

Área de Estudo - A costa de Pernambuco está inserida na margem continental nordeste do Brasil, com aproximadamente $180 \mathrm{~km}$ de extensão norte-sul, localizando-se, entre as latitudes $07^{\circ} 30^{\prime} \mathrm{N}$ e $09^{\circ} 00^{\prime} \mathrm{S}$. O clima da região, segundo a classificação de Koeppen, é o tipo A' (Macêdo et al. 2004), ocorrendo dois períodos anuais: o período chuvoso (março-agosto), com precipitação mensal em torno de $100 \mathrm{~mm}$, e o período seco (setembro-fevereiro), geralmente com precipitação abaixo de $100 \mathrm{~mm}$. A temperatura média anual fica em torno de $27{ }^{\circ} \mathrm{C}$ (Araújo et al. 2004). No litoral de Pernambuco, na região entre-marés, os substratos consolidados estão representados, predominantemente, pelos recifes de franja, formando cordões paralelos à costa, constituindo-se em diques naturais nem sempre emersos nas marés baixas (Pereira et al. 2002). Na costa sul os costões rochosos estão representados em pequenas áreas (Muñoz \& Pereira 1997).

O Arquipélago de Fernando de Noronha está situado no Atlântico Sul Equatorial a $03^{\circ} 51^{\prime} \mathrm{S}$ e $32^{\circ} 25^{\prime} \mathrm{W}$, distando 345 km do Cabo de São Roque (RN) e 545 km da cidade de Recife (PE). É formado por uma ilha principal que lhe garante o nome, com cerca de $16,4 \mathrm{~km}^{2}$, representando $91 \%$ da área do arquipélago. O clima é do tipo Awi segundo o sistema de classificação de Koeppen. A média anual de temperatura fica em torno de $25^{\circ} \mathrm{C}$ com a ocorrência de ventos alísios e precipitação em torno de $1.400 \mathrm{~mm}$. Durante o ano ocorrem duas estações bem definidas, a chuvosa de fevereiro a julho e a seca de agosto a janeiro (Villaça et al. 2006).

Material - Foram realizadas coletas no período de abril/2004 a novembro/2005 e abril, junho e setembro/2006, ao longo do litoral de Pernambuco, tendo sido visitadas 32 praias (Tab. 1). O material foi coletado na região entre marés, durante as marés baixas, com o auxílio de espátulas e, quando necessário, equipamentos de mergulho. No Arquipélago de Fernando de Noronha as coletas foram realizadas em oito praias, no mês de junho/2005, na região entre marés e no infralitoral, nas isóbatas de 10,15 e $21 \mathrm{~m}$. Os pontos de coleta foram marcados com o auxílio de GPS (Global Positioning System). Foram utilizadas, para o deslocamento quando necessário, pequenas embarcações tipo jangadas e/ou baiteiras e barcos a motor.

As plantas foram fixadas em solução de formol (4\%), neutralizadas com bórax (1\%) e devidamente acondicionadas em recipientes de vidro, para posterior identificação taxonômica. As coletas foram complementadas pela análise de 461 exsicatas de Caulerpa depositadas no Herbário Professor Vasconcelos Sobrinho (PEUFR) da Universidade Federal Rural de Pernambuco (UFRPE) coletadas na costa de Pernambuco durante o período de dezembro/1957 a agosto/2004. O material ficológico coletado foi analisado no laboratório de Ficologia (LABOFIC) da UFRPE. No texto, é apresentada, quando possível, uma média de 10 medições por estrutura (diâmetro do estolão, diâmetro e largura dos ramos, diâmetro e largura dos râmulos ou pínulas), constando de mínima, média entre parênteses e máxima. Para a identificação foi utilizada bibliografia pertinente (Coppejans 1992; Meñez \& Calumpong 1982; Durand et al. 2002; Oliveira et al. 2005; De Clerck et al. 2005). Para o posicionamento dos táxons seguiu-se Wynne 
Tabela 1. Localização das estações de coleta no litoral de Pernambuco e Arquipélago de Fernando de Noronha, Brasil (coordenadas citadas conforme programa Google Earth).

\begin{tabular}{|c|c|c|c|c|c|}
\hline Estações / Coordenadas & Latitude & Longitude & Estações / Coordenadas & Latitude & Longitude \\
\hline \multicolumn{6}{|l|}{ Litoral Norte } \\
\hline Pr. Jaguaribe & $7^{\circ} 44^{\prime} \mathrm{S}$ & $34^{\circ} 49^{\prime} \mathrm{W}$ & Pr. Calhetas & $8^{\circ} 21^{\prime} \mathrm{S}$ & $34^{\circ} 50^{\prime} \mathrm{W}$ \\
\hline Pr. Ponta de Pedras & $7^{\circ} 38^{\prime} \mathrm{S}$ & $34^{\circ} 48^{\prime} \mathrm{W}$ & Pr. Gaibú & $8^{\circ} 19^{\prime} \mathrm{S}$ & $34^{\circ} 57^{\prime} \mathrm{W}$ \\
\hline Pr. Carne de Vaca & $7^{\circ} 35^{\prime} \mathrm{S}$ & $34^{\circ} 49^{\prime} \mathrm{W}$ & Pr. Porto de Galinhas & $8^{\circ} 30^{\prime} \mathrm{S}$ & $35^{\circ} 00^{\prime} \mathrm{W}$ \\
\hline Pr. Tabatinga & $7^{\circ} 36^{\prime} \mathrm{S}$ & $34^{\circ} 49^{\prime} \mathrm{W}$ & Pr. Pedra de Xaréu & $8^{\circ} 18^{\prime} \mathrm{S}$ & $34^{\circ} 56^{\prime} \mathrm{W}$ \\
\hline Pr. Catuama & $7^{\circ} 41^{\prime} \mathrm{S}$ & $34^{\circ} 50^{\prime} \mathrm{W}$ & Pr. Serrambí & $8^{\circ} 33^{\prime} \mathrm{S}$ & $35^{\circ} 01^{\prime} \mathrm{W}$ \\
\hline Pr. Pilar & $7^{\circ} 45^{\prime} \mathrm{S}$ & $34^{\circ} 49^{\prime} \mathrm{W}$ & Pr. Paraiso & $8^{\circ} 21^{\prime} \mathrm{S}$ & $34^{\circ} 57^{\prime} \mathrm{W}$ \\
\hline Pr. Forte Orange & $7^{\circ} 48^{\prime} \mathrm{S}$ & $34^{\circ} 49^{\prime} \mathrm{W}$ & Pr. Suape & $8^{\circ} 21^{\prime} \mathrm{S}$ & $34^{\circ} 57^{\prime} \mathrm{W}$ \\
\hline Pr. Maria Farinha & $7^{\circ} 52^{\prime} \mathrm{S}$ & $34^{\circ} 50^{\prime} \mathrm{W}$ & Pr. Muro Alto & $8^{\circ} 24^{\prime} \mathrm{S}$ & $34^{\circ} 58^{\prime} \mathrm{W}$ \\
\hline Pr. Conceição & $7^{\circ} 55^{\prime} \mathrm{S}$ & $34^{\circ} 49^{\prime} \mathrm{W}$ & Pr. Cupe & $8^{\circ} 27^{\prime} \mathrm{S}$ & $34^{\circ} 57^{\prime} \mathrm{W}$ \\
\hline Pr. Nossa Senhora do Ó & $7^{\circ} 54^{\prime} \mathrm{S}$ & $34^{\circ} 49^{\prime} \mathrm{W}$ & Pr. Tamandaré & $8^{\circ} 44^{\prime} \mathrm{S}$ & $35^{\circ} 06^{\prime} \mathrm{W}$ \\
\hline Pr. Pau Amarelo & $7^{\circ} 53^{\prime} \mathrm{S}$ & $34^{\circ} 50^{\prime} \mathrm{W}$ & Pr. São José da Coroa Grande & $8^{\circ} 53^{\prime} \mathrm{S}$ & $35^{\circ} 09^{\prime} \mathrm{W}$ \\
\hline Pr. Rio Doce & $8^{\circ} 00^{\prime} \mathrm{S}$ & $34^{\circ} 51^{\prime} \mathrm{W}$ & Ilha de Santo Aleixo & $8^{\circ} 36^{\prime} \mathrm{S}$ & $35^{\circ} 01^{\prime} \mathrm{W}$ \\
\hline Pr. Casa Caiada & $8^{\circ} 00^{\prime} \mathrm{S}$ & $34^{\circ} 51^{\prime} \mathrm{W}$ & \multicolumn{3}{|l|}{ Arquipélago de Fernando de Noronha } \\
\hline Litoral Sul & & & Buraco do Inferno & $3^{\circ} 51^{\prime} \mathrm{S}$ & $32^{\circ} 26^{\prime} \mathrm{W}$ \\
\hline Pr. Pina & $8^{\circ} 04^{\prime} \mathrm{S}$ & $34^{\circ} 52^{\prime} \mathrm{W}$ & Enseada do Cação & $3^{\circ} 50^{\prime} \mathrm{S}$ & $32^{\circ} 24^{\prime} \mathrm{W}$ \\
\hline Pr. Boa Viagem & $8^{\circ} 09^{\prime} \mathrm{S}$ & $34^{\circ} 54^{\prime} \mathrm{W}$ & Buraco da Cabra & $3^{\circ} 50^{\prime} \mathrm{S}$ & $32^{\circ} 25^{\prime} \mathrm{W}$ \\
\hline Pr. Piedade & $8^{\circ} 10^{\prime} \mathrm{S}$ & $34^{\circ} 54^{\prime} \mathrm{W}$ & Laje Dois Irmãos & $3^{\circ} 50^{\prime} \mathrm{S}$ & $32^{\circ} 26^{\prime} \mathrm{W}$ \\
\hline Pr. Candeias & $8^{\circ} 12^{\prime} \mathrm{S}$ & $34^{\circ} 56^{\prime} \mathrm{W}$ & Biboca & $3^{\circ} 51^{\prime} \mathrm{S}$ & $32^{\circ} 26^{\prime} \mathrm{W}$ \\
\hline Pr. Barra de Jangada & $8^{\circ} 14^{\prime} \mathrm{S}$ & $34^{\circ} 55^{\prime} \mathrm{W}$ & Pr. do Atalaia & $3^{\circ} 49^{\prime} \mathrm{S}$ & $32^{\circ} 24^{\prime} \mathrm{W}$ \\
\hline Pr. Itapuama & $8^{\circ} 21^{\prime} \mathrm{S}$ & $34^{\circ} 57^{\prime} \mathrm{W}$ & Pr. do Sancho & $3^{\circ} 49^{\prime} \mathrm{S}$ & $32^{\circ} 27^{\prime} \mathrm{W}$ \\
\hline Pr. Enseada dos Corais & $8^{\circ} 18^{\prime} \mathrm{S}$ & $34^{\circ} 58^{\prime} \mathrm{W}$ & Boldró & $3^{\circ} 50^{\prime} \mathrm{S}$ & $32^{\circ} 25^{\prime} \mathrm{W}$ \\
\hline
\end{tabular}

(2005). As ilustrações dos táxons foram feitas através de fotografias dos exemplares in natura e/ou herborizados.

\section{Resultados}

\section{Caulerpa Lamouroux}

Desv. J. Bot. 2, p.138, 1809

Talo cenocítico, constituído por porção estolonífera, tendo, na sua parte inferior, tufos de rizóides e na superior, ramos eretos com forma variada. A sustentação é feita por trabéculas de celulose, ramificadas ou não, que se estendem de parede a parede, atravessando o citoplasma em todas as direções. Os cloroplastos são numerosos e discóides. Reprodução sexual por anisogametas biflagelados, produzidos em porções não modificadas do talo e sem a formação de septos; os gametas são liberados através de papilas, onde se abrem poros. Não há alternância de gerações. (Taylor 1960).

Chave para a identificação das espécies de Caulerpa

1. Talo filamentoso, com pouca diferenciação entre o estolão e os ramos assimiladores

1. Talo não filamentoso, com marcada diferenciação entre o estolão e os ramos assimiladores

2. Talo com ramos assimiladores indivisos semelhantes a "folha" ou fita estreita ou, ainda, divididos em râmulos (pínulas)

2. Talo com ramos assimiladores portando râmulos mamiliformes, piriformes a subglobosos

3. Ramos com margens lisas, ápices arredondados a levemente emarginados

3. Ramos com margens denteadas ou não, râmulos cilíndricos ou achatados

4. Ramos assimiladores, semelhantes a "fita" com margens, tipicamente denteadas ...... 10. C. serrulata

4. Ramos assimiladores não em forma de "fita"

5. Ramos revestidos por râmulos filiformes, ápices mucronados, densamente dispostos impedindo a visualização do eixo principal

5. Ramos portando râmulos dispostas de maneira diversa

6. Râmulos distribuídos em vários planos

6. Râmulos distribuídos em um único plano 
7. Râmulos mamiliformes a subnaviculares ……........................................... 1. Cupressoides

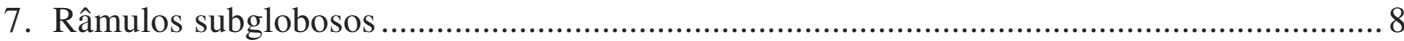

8. Râmulos piriformes a clavadas distribuídas de maneira dística ou trística ao redor do eixo central 9. C. racemosa

8. Râmulos geralmente reunidas em grupos de três ou irregular, dispostas radialmente em torno do eixo central ................................................... 6. C. microphysa 9. Pínulas de 3,2-(4,8)-5,9 mm compr., levemente curvadas em direção ao eixo, constritas na base, ápices ponteagudos 5. C. mexicana

9. Pínulas de 1,8-(2,1)-3,5 mm compr., marcadamente recurvadas em direção ao eixo, não constrictas na base 10. Pínulas dispostas característicamente, de forma dística ....... 11. C. sertularioides 10. Pínulas dispostas em verticilos

11. Ápices dos râmulos de última ordem emarginados, mucronados, bimucronados divergentes

11. Ápices dos ramos de última ordem bimucronados não divergentes, ponteagudos 12

12. Râmulos com marcada constricção na base das dicotomias e estolão recoberto por rizóides

1. Caulerpa cupressoides var. lycopodium (J. Agardh) Weber van Bosse, Spec. Alg., p. 441. 1823

Fucus cupressoides Vahl. Skrift. Naturh.- Selsk. p. 29. 1802

$\mathrm{Na}$ flora estudada Caulerpa cupressoides var. lycopodium ocorreu com duas formas reconhecidas pela seguinte chave:

1a. Râmulos dispostos em várias fileiras em torno do eixo principal f. lycopodium

2a. Râmulos dispostos de forma dística e/ou trística f. disticha

\subsection{Caulerpa cupressoides var. lycopodium (J. Agardh)} Weber van Bosse f. lycopodium, Monog. p. 28. 1898 Caulerpa lycopodium J. Agardh, Ofvers. K. Vetensk. Akad. Forh., Stockh. p. 6, 1847

Fig. 1-2

Plantas com 2,0-(7,6)-14,2 cm alt. Estolão glabro, cilíndrico, ramificado, geralmente, com cerca de 1,5 mm diâm. Rizóides ramificados. Ramos assimiladores cilíndricos, ramificados, eixos com 2,0-(3,2)-4,2 mm diâm., desnudos na porção basal e acima revestidos por várias fileiras de râmulos, distribuídos de maneira compacta e ao redor do eixo central, sésseis, levemente a marcadamente pedunculados. Râmulos basais mamiliformes com ápices mucronados e dispostos de maneira esparsa. A partir da porção mediana, râmulos dispostos de forma compacta, longos, cilíndricos e ápices mucronados, com 0,5-(0,7)-1,1 mm larg. sempre curvados em direção ao eixo principal.

Material examinado: BRASIL. Pernambuco: Ilha de Itamaracá, Praia de Jaguaribe, 28/IX/2004, S.G.
Brayner-Barros, S.M.B. Pereira \& M.E. BandeiraPedrosa (PEUFR48220). Goiana, Praia de Ponta de Pedras, 18/X/2005, S.G. Brayner-Barros, S.M.B. Pereira \& P.R.F. Nascimento, (PEUFR48221). Cabo de Santo Agostinho, Praia de Gaibú, 15/IX/2004, S.G. BraynerBarros, S.M.B. Pereira \& D.C. Burgos (PEUFR48226). Cabo de Santo Agostinho, Praia de Pedra de Xaréu, 4/X/2005, S.G. Brayner-Barros \& S.M.B. Pereira (PEUFR48227). Ipojuca, Praia de Serrambí, 20/IX/2005, S.G. Brayner-Barros \& S.M.B. Pereira (PEUFR48228).

Os exemplares foram coletados, apenas, nas praias do litoral de Pernambuco, principalmente, em substrato arenoso, em locais protegidos (Tab. 2). Alguns espécimes serviram como hospedeiros para Halimeda opuntia (L.) Lamour., Dictyota menstrualis (Hoyt) Schnetter, Hörnig \& Weber-Peukert, Dictyopteris delicatula Lamour., Hypnea musciformis (Wulfen in Jacquin) Lamour., Corallina sp.

\subsection{Caulerpa cupressoides var. lycopodium f. disticha}

Weber van Bosse, Mong. Caul. p. 338. 1898

Fig. 3-4

Plantas com 5,5-(6,8)-8,8 cm alt. Estolão glabro, cilíndrico, ramificado, com 1,0-(1,7)-2,5 mm diâm. Rizóides ramificados. Ramos assimiladores cilíndricos, ramificados, desnudos na porção basal e acima cobertos por râmulos. Râmulos distribuídos ao longo do eixo, dispostos dísticamente, as vezes de maneira trística, nas porções basal, mediana e apical. Râmulos acima da porção basal subnaviculares deixando uma maior distância entre si. Eixos dos râmulos mais superiores com 0,5(1,7)3,1 mm compr., e largura de 0,5-(0,7)-1,1 mm 
Tabela 2. Distribuição dos representantes de Caulerpa Lamouroux, coletados no período de abril/2004 a novembro/2005, no litoral de Pernambuco e Arquipélago de Fernando de Noronha, Brasil. (L.N. - Litoral Norte; L.S. - Litoral Sul e F.N. - Fernando de Noronha). + = presença, - = ausência.

\begin{tabular}{|c|c|c|c|c|}
\hline Táxons & L.N. & L.S. & F.N. & Localidade/Praia \\
\hline C. cupressoides var. lycopodium f. lycopodium & + & + & - & Jaguaribe; Ponta de Pedra; Gaibú; Pedra de Xaréu e Serrambí \\
\hline C. cupressoides var. lycopodium $\mathrm{f}$. disticha & + & + & - & Ponta de Pedra; Boa Viagem; Itapuama e Tamandaré \\
\hline C. fastigiata & - & - & - & Herbário PEUFR \\
\hline C. kempfii & + & - & & Jaguaribe e Ponta de Pedra \\
\hline C. lanuginosa & + & - & - & Jaguaribe e Ponta de Pedra \\
\hline C. mexicana & + & + & - & Jaguaribe; Boa Viagem; Candeias e Pedra de Xaréu \\
\hline C. microphysa & - & + & - & Serrambí e Ilha de Santo Aleixo \\
\hline C. prolifera & + & + & - & Ponta de Pedra; Catuama; Conceição e Serrambí \\
\hline C. pusilla & - & - & + & Buraco do Inferno; Enseada do Cação; Laje Dois Irmãos e Sancho \\
\hline C. racemosa var. racemosa & + & + & - & $\begin{array}{l}\text { Carne de Vaca; Conceição; Porto de Galinhas; Tamandaré e Ilha de } \\
\text { Santo Aleixo }\end{array}$ \\
\hline C. racemosa var. occidentalis & + & + & - & Ponta de Pedra; Carne de Vaca; Pilar; Itapuama e Serrambí \\
\hline C. racemosa var. peltata & - & + & - & Porto de Galinhas; Serrambí e Cupe \\
\hline C. serrulata & - & + & - & Serrambí \\
\hline C. sertularioides & + & + & - & Jaguaribe; Pilar; Conceição; Pina e Gaibú \\
\hline C. verticillata & - & - & + & $\begin{array}{l}\text { Buraco do Inferno; Enseada do Cação; Laje Dois Irmãos; Biboca e } \\
\text { Atalaia }\end{array}$ \\
\hline C. webbiana & - & - & + & Boldró \\
\hline
\end{tabular}

diâm. Râmulos cilíndricos e ápices mucronados.

Material examinado: BRASIL. Pernambuco: Goiana, Praia de Ponta de Pedras, 18/X/2005, S.G. Brayner-Barros \& S.M.B. Pereira (PEUFR48230). Recife, Praia de Boa Viagem, 7/V/2005, S.G. BraynerBarros \& P.R.F. Nascimento (PEUFR48231). Cabo de Santo Agostinho, Praia de Itapuama, 6/V/2005, S.G. Brayner-Barros \& F.A. Ribeiro (PEUFR48232). Tamandaré, Praia de Tamandaré, 10/XII/2004, S.G. Brayner-Barros \& S.M.B. Pereira (PEUFR48233).

Os exemplares foram coletados tanto no litoral sul quanto no norte de Pernambuco, principalmente em substrato rochoso (Tab. 2). Os espécimes ocorreram em associações com outras macroalgas como Halimeda opuntia, Dictyota menstrualis, Dictyopteris delicatula, Hypnea musciformis.

2. Caulerpa fastigiata Montagne, Hist. Nat. Cuba. p. 19. 1838

Fig. 5

Plantas com talo filamentoso, com 2,0-(2,4)-2,5 cm alt. Ramos assimiladores cilíndricos, ramificados, completamente desnudos com $0,5 \mathrm{~mm}$ diâm., com pouca diferenciação entre o estolão e os ramos. Filamentos, próximos ao ápice, com ramificação de oposta a irregular.

Material examinado: BRASIL. Pernambuco: Ilha de Itamaracá, Praia de Vila Velha, 21/XII/1987, L.B. Paes e Mello (PEUFR25411).

A análise do material está baseada numa única exsicata coletada no litoral norte de Pernambuco (Tab. 2).
3. Caulerpa kempfii Joly et Pereira, Ciênc. e Cult. p. 417. 1975

Fig. 6

Planta com altura variando entre $1,5(2,4)$ e $3,0 \mathrm{~cm}$. Estolão cilíndrico intensamente ramificado, totalmente recoberto por pêlos lanuginosos, com cerca de $1,5 \mathrm{~mm}$ diâm. Pêlos ramificados dicotomicamente ou de maneira irregular. Eixos principais, cilíndricos, bastante ramificados, com diâmetro de $1,2 \mathrm{~cm}$, recobertos por pêlos. Os ramos assimiladores se iniciam nas ramificações de última ordem dos eixos principais e podem estar dispostos em verticilos ou de maneira espiralada irregular, com diâmetro de $2,0 \mathrm{~mm}$. Os verticilos com largura de $2,0 \mathrm{~mm}$. Os râmulos de última ordem com ápices emarginados, mucronados ou até bimucronados, com múcrons divergentes.

Material examinado: BRASIL. Pernambuco: Goiana, Praia de Ponta de Pedras, 7/V/1997, M.F. Oliveira-Carvalho \& P.R.F. Nascimento (PEUFR30980). Ilha de Itamaracá, Praia de Jaguaribe, 7/VI/1997, M.F.B. Oliveira \& D.R. Cavalcanti (PEUFR24615). Ilha de Itamaracá, Praia de Jaguaribe, 17/IX/1997, M.F. Oliveira-Carvalho \& P.R.F. Nascimento (PEUFR30994). Goiana, Praia de Ponta de Pedras, 18/IX/1997, M.F.B. Oliveira \& D.R. Cavalcanti (PEUFR24699). Ilha de Itamaracá, Praia de Jaguaribe, 14/XI/1997, M.F. Oliveira-Carvalho \& P.R.F. Nascimento (PEUFR24641).

A espécie parece ter uma área de ocorrência restrita no litoral norte de Pernambuco (Tab. 2). Foi observada crescendo sobre substrato rochoso. 
4. Caulerpa lanuginosa J. Agardh, Till Alg. Syst. p. 28. 1872

Fig. 7-8

Plantas com altura variando entre 8,5-(15,8)-21 cm. Estolão cilíndrico recoberto por pêlos lanuginosos, densamente dispostos preenchidos por partículas do substrato, com 3-(3,2)-3,5 mm diâm. Estes pêlos estão dispostos da base dos ramos assimiladores, até a altura de $7 \mathrm{~cm}$. Ramos assimiladores revestidos de râmulos filiformes, com ápices mucronados, densamente dispostos impedindo a visualização do eixo principal. Râmulos basais com comprimento entre 1,4-(1,3)-1,6 mm e os superiores com 1,6-(1,7)-2,1 mm, com diâmetro de 5,5-(6,3)-8,4 mm.

Material examinado: BRASIL. Pernambuco: Goiana, Praia de Ponta de Pedras, 11/XII/1984, R.L. Silva
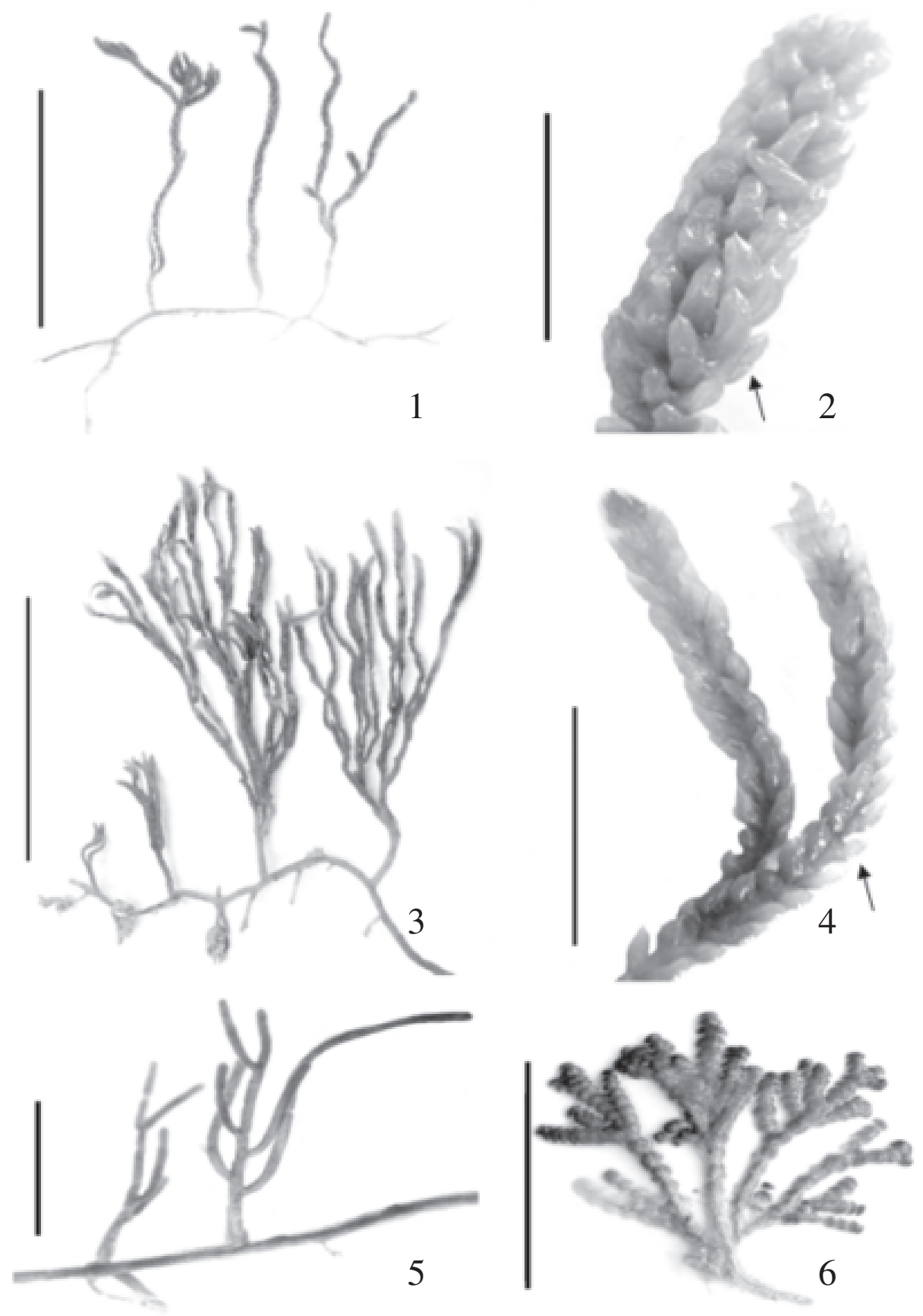

Figuras 1-2. Caulerpa cupressoides var. lycopodium f. lycopodium Weber Bosse. 1. Aspecto geral da planta. 2. Detalhe da morfologia dos ramos assimiladores. Observe detalhe do râmulo (seta). 3-4. Caulerpa cupressoides var. lycopodium f. disticha Weber Bosse. 3. Aspecto geral da planta. 4. Detalhe da morfologia dos ramos assimiladores. Note presença de ramificação trística nos ramos. Detalhe do râmulo ponteagudo (seta). 5. Caulerpa fastigiata Mont. - Aspecto geral da planta. 6. Caulerpa kempfii Joly et Pereira. Aspecto geral da planta. Barras $=1 \mathrm{~cm}$. 
(PEUFR7838). Ilha de Itamaracá, Praia de Jaguaribe, 11/VIII/1995, M.F.B. Oliveira (PEUFR21637). Goiana, Praia de Ponta de Pedras, 17/XI/1997, M.F.B. Oliveira \& D.R. Cavalcanti (PEUFR24625). Goiana, Praia de Ponta de Pedras, 18/X/2005, S.G. Brayner-Barros, S.M.B. Pereira \& M.E. Bandeira-Pedrosa (PEUFR48234).

As plantas foram encontradas crescendo sobre substrato arenoso nas praias de Ponta de Pedras e Jaguaribe (litoral norte) (Tab. 2).

5. Caulerpa mexicana Sonder ex Kützing, Sp. Alg. p. 496.1849

Fig. 9-10

Plantas com 1,6-(3,5)-7,4 cm alt. Estolão glabro, cilíndrico, as vezes ramificados, com cerca de 0,5-(1,1)-1,5 mm diâm. Rizóides ramificados. Ramos assimiladores com forma lanceolada, base levemente pedunculada, pedúnculo cilíndrico, com 4,3-(5,9)-6,2 cm alt. e 3,4-(4,6)-5,7 cm larg. Ramos divididos em pínulas, dispostos disticamente ao longo de uma "nervura central". As pínulas 3,2-(4,8)-5,9 mm compr., levemente recurvadas, constritas na base, ápices ponteagudos.

Material examinado: BRASIL. Pernambuco: Ilha de Itamaracá, Praia de Jaguaribe, 28/IX/2004, S.M.B. Pereira, S.G. Brayner-Barro \& M.E. Bandeira-Pedrosa (PEUFR48235). Recife, Praia de Boa Viagem, 7/V/2005, S.G. Brayner-Barros \& P.R.F. Nascimento (PEUFR48241). Candeias, Praia de Candeias, 6/V/2005, S.G. Brayner-Barros \& P.R.F. Nascimento (PEUFR48242). Cabo de Santo Agostinho, Praia de Pedra de Xaréu, 4/X/2005, S.G. Brayner-Barros, S.M.B. Pereira \& M.F. OliveiraCarvalho (PEUFR48243).

Os exemplares ocorreram principalmente, em substrato arenoso, em locais protegidos (poça aberta), em associação com Hypnea musciformis.

6. Caulerpa microphysa (Weber van Bosse) Feldmann, Rev. Gén. Bot. p. 422-431. 1955

Caulerpa racemosa f. microphysa Weber van Bosse, Ann. Jard. Bot. Buitenz. p. 243-401. 1898

Fig. 11-12

Plantas com 0,5-(1,9)-2,5 cm alt. Estolão glabro, cilíndrico, ramificado, com 1,0-(1,4)-1,5 mm diâm. Ramos assimiladores cilíndricos, ramificados, eixos com 0,5-(0,9)-1,0 mm, desnudos na porção basal e acima por râmulos geralmente reunidos em grupos de três ou às vezes de forma irregular, dispostos radialmente em torno do eixo central, formando densos emaranhados. Râmulos subglobosos medindo 0,3-(0,8)-1,2 mm larg., inicialmente subsésseis, e a partir da porção mediana, curtos pedúnculos.

Material examinado: BRASIL. Pernambuco: Ilha de Santo Aleixo, 12/XII/2004, S.M.B. Pereira et al.
(PEUFR48306). Ipojuca, Praia de Serrambí, 9/IX/2006, M.E. Bandeira-Pedrosa (PEUFR48307).

Espécie com pouca ocorrência no litoral sul de Pernambuco (Tab. 2), sendo, este o seu segundo registro. A primeira referência para o estado foi para Cabo de Santo Agostinho, litoral sul (SPF 87) (Pereira et al. 2002). No litoral brasileiro foi coletado também em Cabo Frio (RJ) para as praias de Fornos (SPF 86) e de Peró (SPF 88). As plantas analisadas ocorreram sobre substrato rochoso em associação Codium repens Vickers, Sargassum polyceratium, Bryothamniom triquetum e Gracilaria sp.

7. Caulerpa prolifera (Forsskaal) Lamouroux, Desvaux. J. Bot. Paris. p. 130. 1809

Fucus prolifer Forsskaal Flor. Aegyp. Arab. p. 139. 1775 Fig. 13-14

Plantas com 5,1-(7,7)-11,8 cm alt. Estolão glabro, cilíndrico, ramificado, com cerca de 0,5-(1,2)-2,0 mm diâm. Rizóides não ramificados. Ramos assimiladores pedunculados, achatados, com ou sem proliferações, eixos com 4,7-(6,1)-8,5 mm diâm., desnudos na porção basal e acima, formando finas expansões laminares, semelhante a "folhas", com formato lanceolado, margens lisas, ápice arredondado a levemente emarginado.

Material examinado: BRASIL. Pernambuco: Goiana, Praia de Ponta de Pedras, 18/X/2005, S.G. Brayner-Barros, S.M.B. Pereira \& P.R.F. Nascimento (PEUFR48246). Goiana, Praia de Catuama, 7/IV/2005, S.G. Brayner-Barros (PEUFR48248). Paulista, Praia de Conceição, 23/III/2004, S.G. Brayner-Barros \& P.R.F. Nascimento (PEUFR48251). Ipojuca, Praia de Serrambí, 20/IX/2005, S.G. Brayner-Barros \& P.R.F. Nascimento (PEUFR48253).

Os exemplares ocorreram principalmente em substrato arenoso, em locais protegidos, servindo como hospedeiro para outras macroalgas como Dictyota menstrualis, Dictyopteris delicatula, Hypnea musciformis, Corallina sp.

8. Caulerpa pusilla (Kützing) Martius et Hering (11) ex J. Agardh, Till Alg. Syst. p. 6. 1872

Stephanocoelium pusillum Kützing, Bot. Ztg. p. 5, 1847

Fig. 15-16

Plantas com altura variando entre 1,5-(2,3)-3,0 cm. Estolão cilíndrico, totalmente recoberto por rizóides, ramificados, com 1,4 mm diâm. Ramos assimiladores constituídos por eixos principais, cilíndricos, ramificados, com diâmetro de $1,5 \mathrm{~mm}$, porções superiores com característicos verticilos de râmulos sobrepostos, com diâmetro 1,0 mm e largura de 1,9 mm. Râmulos dicotomicamente divididos até cinco vezes, com marcada constricção na base das dicotomias, ápices bi-mucronados divergentes. 
Material examinado: BRASIL. Pernambuco: Fernando de Noronha, Praia Buraco do Inferno, 25/IV/2006, D.C. Burgos (PEUFR48254). Fernando de Noronha, Praia Enseada do Cação, 25/IV/2006, D.C. Burgos (PEUFR48255). Fernando de Noronha, Praia Laje Dois Irmãos, 27/IV/2006, D.C. Burgos (PEUFR48256). Fernando de Noronha, Praia do Sancho, 14/VI/2006, D.C. Burgos \& P.A. Horta (PEUFR48257).
Os exemplares foram coletados apenas no Arquipélago de Fernando de Noronha (Tab. 2), na região entre marés e no infralitoral. Na região entre marés ocorreram tanto em substrato arenoso como consolidado. No infralitoral, nas profundidades de 10, 15 e 21 m, em substratos arenosos formando densos tapetes. Tanto no infralitoral como na região entre marés abrigavam epífitas como Halimeda opuntia, Dictyopteris delicatula, Hypnea musciformis.
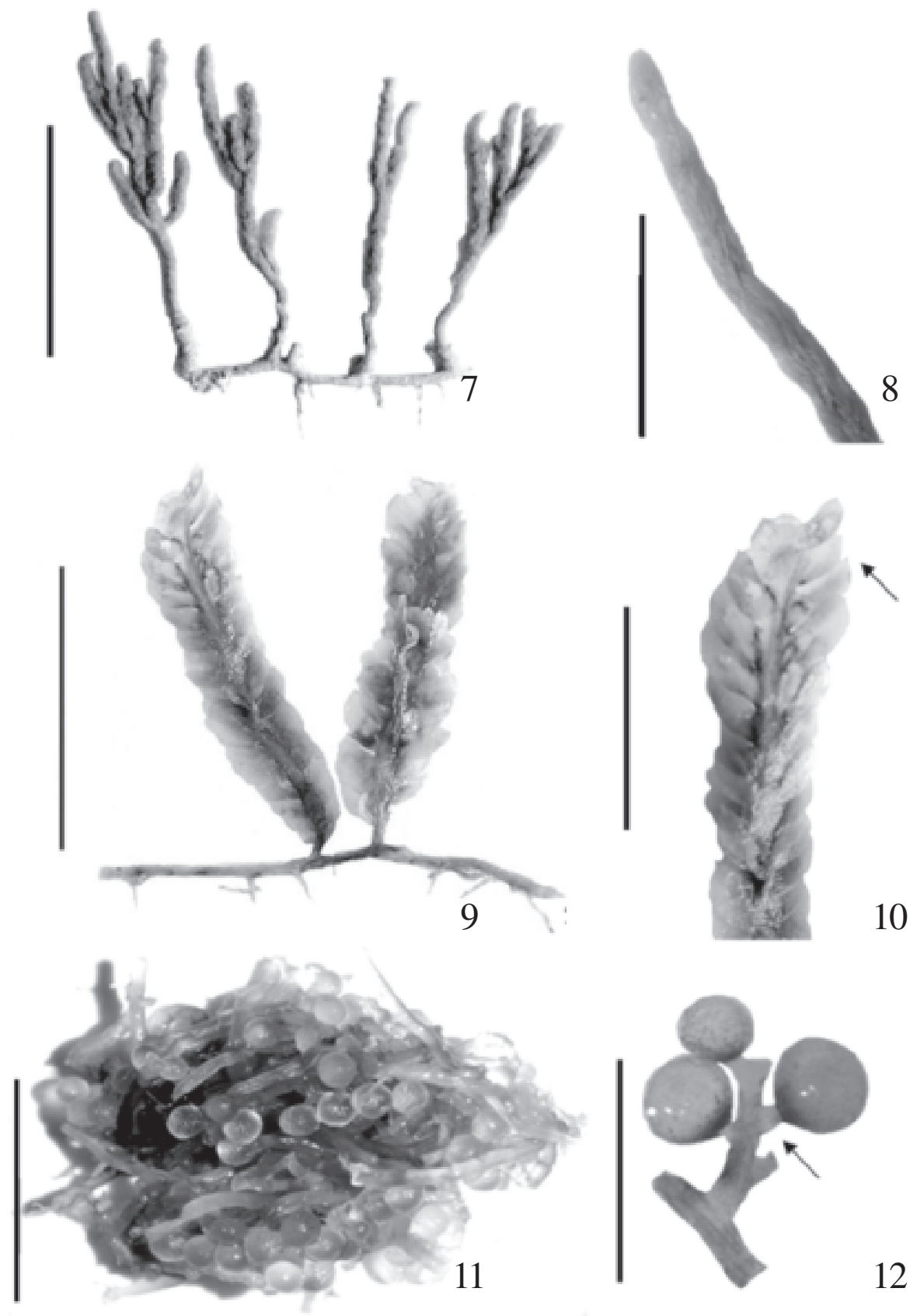

Figuras 7-8. Caulerpa lanuginosa J. Agardh. 7. Aspecto geral da planta. 8. Detalhe do ramo assimilador recoberto por pêlos ou râmulos lanuginosos. 9-10. Caulerpa mexicana Sond. ex Kütz. 9. Aspecto geral da planta. 10. Detalhe dos ramos assimiladores com forma lanceolada. Note detalhe do múcron (seta). 11-12. Caulerpa microphysa (Weber van Bosse) Feldmann. 11. Aspecto geral da planta. 12. Detalhe dos râmulos subglobosos, reunidos em grupos de três. Detalhe do râmulo subséssil (seta). Barras = (7-11) $1 \mathrm{~cm} ;$ (12) $1 \mathrm{~mm}$. 
As variedades de $C$. racemosa podem ser identificadas pela seguinte chave:

1a. Râmulos piriformes a subglobosos

8. var. racemosa

1b. Râmulos de forma diversa..... 2

2a.Râmulos clavados com longo pedúnculo $(2,5 \mathrm{~mm})$........ 8.1 var. occidentalis

2b. Râmulos peltados com curto pedúnculo $(1 \mathrm{~mm})$.................... 8.2 var. peltata

9. Caulerpa racemosa (Forsskaal) J. Agardh var. racemosa, Till Alg. Syst. p. 35. 1872.

Fucus racemosus Forsskaal Flor. Aegyp. Arab. p. 191. 1775.

Fig. 17-18

Plantas com 1,9-(2,9)-4,7 cm alt. Estolão glabro, cilíndrico, ramificado, com 1,5-(1,7)-2,5 mm diâm. Rizóides ramificados. Ramos assimiladores constituídos por um eixo central, pouco ramificado com 2,3-(2,8)-3,6 mm diâm. Râmulos distribuídos irregularmente em torno do eixo, ora de maneira dística e então ligeiramente alternos, ora de maneira trística, sempre visível o eixo principal, desnudos na porção basal e acima cobertos por râmulos irregularmente distribuídos. Râmulos piriformes a subglobosos, subsésseis a curtos pedúnculos, ápices dilatados com 1,8-(2,4)-3,1 mm.

Material examinado: BRASIL. Pernambuco: Goiana, Praia de Carne de Vaca, 3/VI/2004, S.G. Brayner-Barros \& P.R.F. Nascimento (PEUFR48276). Paulista, Praia de Conceição, 23/III/2004, S.G. Brayner-Barros \& P.R.F. Nascimento (PEUFR48278). Ipojuca, Praia de Porto de Galinhas, 11/XI/2004, S.G. Brayner-Barros, S.M.B. Pereira \& M.E. Bandeira-Pedrosa (PEUFR48281). Tamandaré, Praia de Tamandaré, 23/VII/2005, S.G. Brayner-Barros \& M.E. Bandeira-Pedrosa (PEUFR48283). Ilha de Santo Aleixo, 12/XII/2004, S.M.B. Pereira et al. (PEUFR48284).

Os exemplares foram coletados tanto na costa pernambucana (litoral norte e sul) como no Arquipélago de Fernando de Noronha (Tab. 2), em substratos rochosos e/ou arenosos. Neste local na região de infralitoral entre 10 e $15 \mathrm{~m}$ de profundidade. As plantas analisadas ocorreram como hospedeiras para Halimeda opuntia, Dictyopteris delicatula, Hypnea musciformis, Osmundaria obtusiloba (C. Agardh) Norris, Amphiroa sp.

9.1. Caulerpa racemosa var. occidentalis (J. Agardh) Borgesen, Mem. Acad. R. Sci. Lettr. Dansk. p. 384. 1907.

Caulerpa chemnitzia var. occidentalis J. Agardh Till Alg. Syst. p. 37, 1872.

Fig. 19-20
Plantas com 1,1-(3,9)-8,2 cm alt. Estolão glabro, cilíndrico, ramificado, geralmente, com 1,5-(2,0)-3,0 mm diâm. Rizóides ramificados. Ramos assimiladores constituídos por um eixo central, pouco ramificado com 2,1-(3,8)-4,9 mm diâm. Râmulos distribuídos irregularmente em torno do eixo. Râmulos clavados, ápices dilatados, com pedúnculo longo de $2,5 \mathrm{~mm}$, com 1,3-(2,3)-3,1 mm. Plantas férteis com papilas situadas em torno do pedúnculo dos râmulos dilatados.

Material examinado: BRASIL. Pernambuco: Goiana, Praia de Ponta de Pedras, 18/X/2005, S.G. Brayner-Barros \& P.R.F. Nascimento (PEUFR48258). Goiana, Praia de Carne de Vaca, 3/VI/2004, S.G. BraynerBarros \& P.R.F. Nascimento (PEUFR48259). Ilha de Itamaracá, Praia do Pilar, 22/III/2004, S.G. BraynerBarros \& M.F. Oliveira-Carvalho (PEUFR48261). Cabo de Santo Agostinho, Praia de Itapuama, 13/X/2004, S.G. Brayner-Barros, S.M.B. Pereira \& F.A. Ribeiro (PEUFR48265). Ipojuca, Praia de Serrambí, 20/IX/2005, S.G. Brayner-Barros \& S.M.B. Pereira (PEUFR48268).

Foi observada a ocorrência de um único exemplar em estágio reprodutivo, coletado na praia de Serrambí (Tab. 2). Ocorreram em substratos rochosos e/ou arenosos. As plantas analisadas abrigavam como epífitas outras macroalgas como Halimeda opuntia, Ulva lactuca L., Dictyota menstrualis, Dictyopteris delicatula, Sargassum polyceratium Mont., Hypnea musciformis, Osmundaria obtusiloba, Bryothamnion triquetrum (Gmel.) Howe, Gelidiella acerosa (Forssk.) Feldmann \& Hamel, Amphiroa sp., Gelidium sp.

9.2. Caulerpa racemosa var. peltata (Lamouroux) Eubank, Univ. Calif. Public. Bot. p. 421. 1946.

Caulerpa peltata Lamouroux Desvaux. J. Bot. p. 145. 1809.

Fig. 21-22

Plantas com 2,1-(5,0)-9,0 cm alt. Estolão glabro, cilíndrico, ramificado, geralmente, com 1,5-(1,7)-2,0 mm diâm. Rizóides ramificados. Ramos assimiladores constituídos por um eixo central, pouco ramificado com 3,2-(4,0)-4,9 mm diâm. Râmulos distribuídos irregularmente em torno do eixo. Râmulos clavados, com pedúnculo curto, $1 \mathrm{~mm}$ compr., ápices achatados, peltados com 1,5-(2,0)-2,2 mm.

Material examinado: BRASIL. Pernambuco: Ipojuca, Praia de Porto de Galinhas, 11/XI/2004, S.G. Brayner-Barros, S.M.B. Pereira \& M.E. BandeiraPedrosa (PEUFR48272). Ipojuca, Praia de Serrambí, 20/IX/2005, S.G. Brayner-Barros, S.M.B. Pereira \& M.E. Bandeira-Pedrosa (PEUFR48273). Ipojuca, Praia de Cupe, 16/IX/2005, S.G. Brayner-Barros, S.M.B. Pereira \& M.E. Bandeira-Pedrosa (PEUFR48274).

Os exemplares ocorreram no litoral sul de Pernambuco (Tab. 2), em substratos rochosos e/ou 
arenosos, servindo como hospedeiras para Halimeda opuntia, Hypnea musciformis, Bryothamnion triquetrum.

10. Caulerpa serrulata (Forsskaal) J. Agardh emend. Boergesen, Mar. Alg. Trop. Subtr. p. 146. 1960. Caulerpa pectinata Kützing, Sp. Algar, p. 495. 1849.

Fig. 23-24

Plantas com 7,5-(8,6)-13,0 cm alt. Estolão glabro, cilíndrico, ramificado, geralmente, com cerca de 1,5 mm diâm. Rizóides ramificados. Ramos assimiladores, estreitos, semelhantes a "fita" com margens, tipicamente, denteadas. Ramos dispostos num mesmo plano e/ou enrolados com 0,5-(1,7)-2,1 mm diâm., distribuídos de maneira dística, cilíndricos, ápices ponteagudos a serrilhados na região próxima ao estolão e acima agudo, com largura de 0,5-(1,2)-1,4 mm.

Material examinado: BRASIL. Pernambuco: Ipojuca, Praia de Serrambí, 15/X/1986, M. da C. Accioly
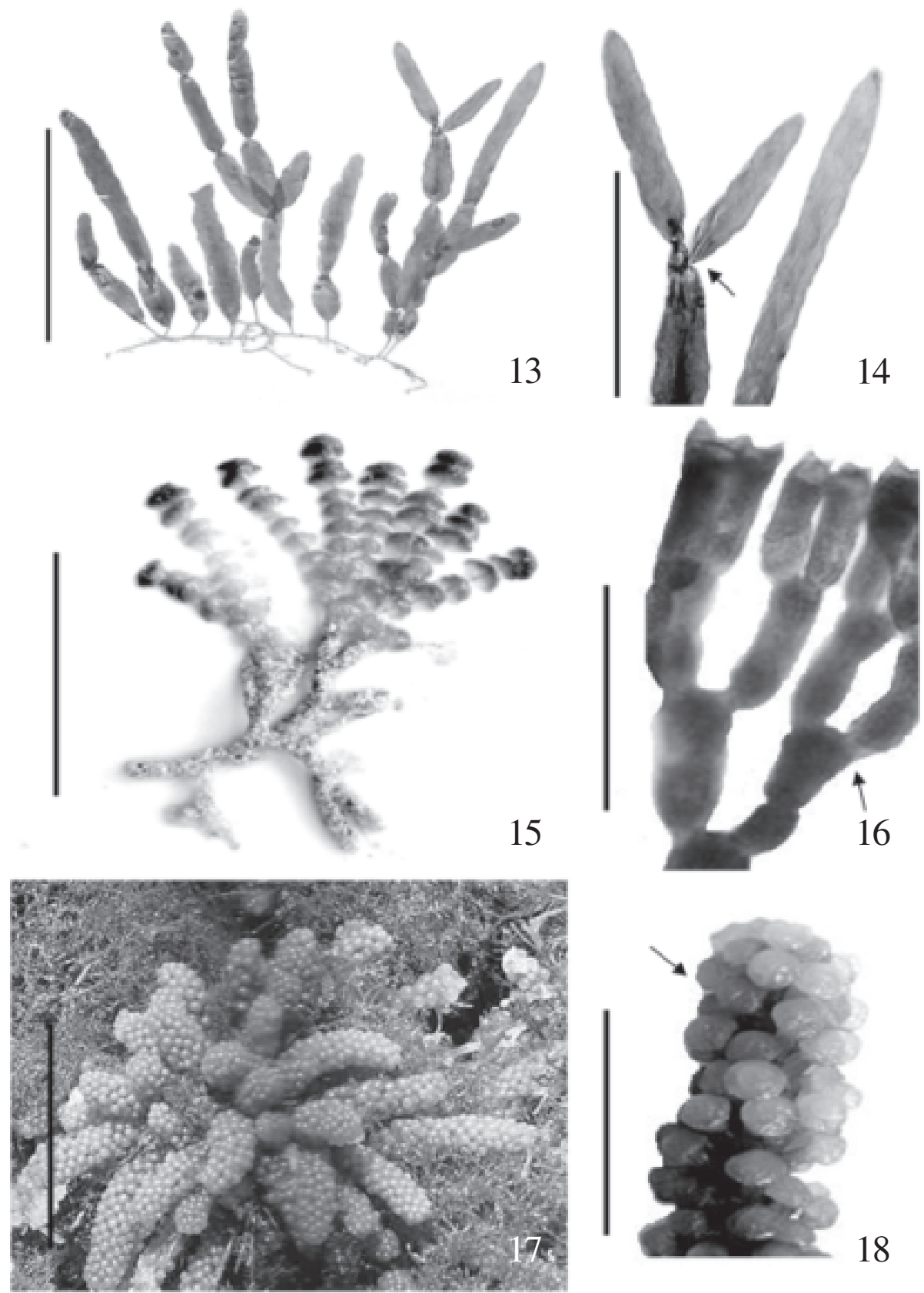

Figuras 13-14. Caulerpa prolifera (Forssk.) J.V. Lamour. 13. Aspecto geral da planta. 14. Detalhe do ramo com proliferação característica (seta). 15-16. Caulerpa pusilla (Kützing) J. Agardh. 15. Aspecto geral da planta. 16. Detalhe do râmulo mostrando marcada constricção nas dicotomias (seta). 17-18. Caulerpa racemosa (Forssk.) J. Agardh var. racemosa. 17. Aspecto geral da planta. 18. Detalhe dos râmulos com ápices dilatados (seta). Barras = $(13-15,17-18) 1 \mathrm{~cm} ;(16) 1 \mathrm{~mm}$. 
(PEUFR12931). Ipojuca, Praia de Serrambí, 25/X/1987, M. da C. Accioly (PEUFR12932). Ipojuca, Praia de Serrambí, 25/X/1987, M. da C. Accioly (PEUFR12933). Ipojuca, Praia de Serrambí, 9/IX/2006, M.E. BandeiraPedrosa (PEUFR48285).

A espécie parece ter sua área de distribuição restrita a praia de Serrambí, no litoral sul de Pernambuco (Tab. 2). Ocorreu em substrato rochoso, abrigando como epífita Dictyopteris delicatula.
11. Caulerpa sertularioides (S.G. Gmelin) Howe, Bull. Torrey Bot. Cl. p. 576. 1905.

Fucus sertularioides Gmelin Hist. Fucorum. p. 151. 1768.

Fig. 25-26

Plantas com 1,3-(12,5)-14,5 cm alt. Estolão glabro, cilíndrico, ramificado, geralmente, com 1,0-(1,4)-2,0 mm diâm. Rizóides ramificados. Ramos assimiladores plumosos, cilíndricos, ramificados, eixos com 4,2-(6,2)-7,7 mm diâm. Ramos desnudos na porção basal
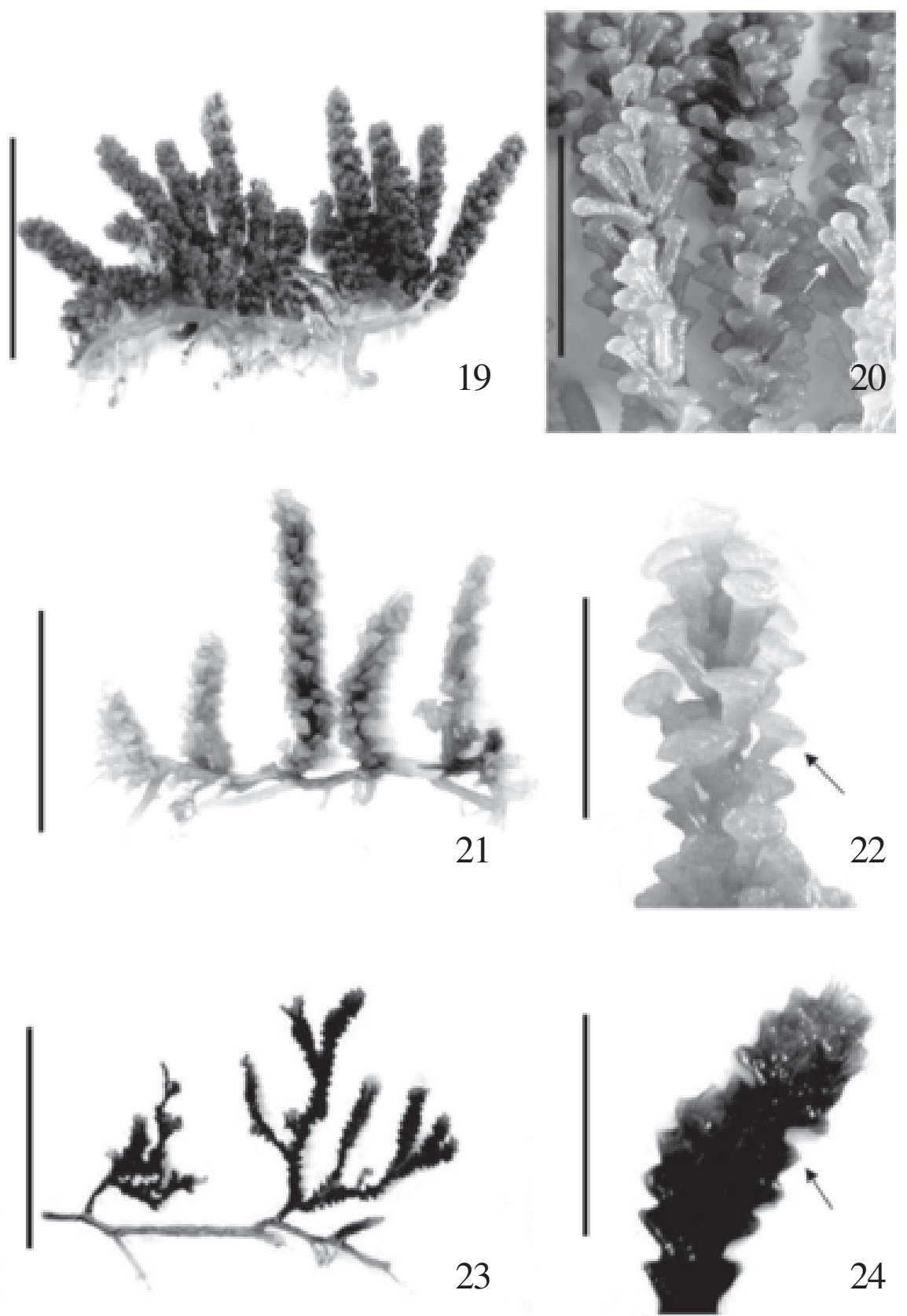

Figuras 19-20. Caulerpa racemosa var. occidentalis (J. Agardh) Boergesen. 19. Aspecto geral da planta. 20. Detalhe dos râmulos clavados (seta) com pedúnculos longos e ápices dilatados. 21-22. Caulerpa racemosa var. peltata (J.V. Lamour.) Eubank. 21. Aspecto geral da planta. 22. Detalhe dos râmulos peltados (seta) com pedúnculos curtos e ápices achatados. 23-24. Caulerpa serrulata (Forssk.) J. Agardh. 23. Aspecto geral da planta. 24. Detalhe do ramo semelhante a "fita" com margens denteadas (seta). Barras = $1 \mathrm{~cm}$. 
e acima, cobertos por râmulos (pínulas), dispostos sempre de maneira dística, em torno de uma "nervura central", com ramificação pinada. Pínulas filiformes, recurvadas, sem constricção, com comprimento de 1,8-(2,1)-3,5 mm e diâmetro de 0,5-(0,7)-1,1 mm. Ápice terminando em múcrom característico.

Material examinado: BRASIL. Pernambuco: Ilha de Itamaracá, Praia de Jaguaribe, 28/IX/2004, S.G. Brayner-Barros, S.M.B. Pereira \& M.E. BandeiraPedrosa (PEUFR48286). Ilha de Itamaracá, Praia do Pilar, 22/III/2004, S.G. Brayner-Barros \& M.F. OliveiraCarvalho (PEUFR48288). Paulista, Praia da Conceição, 23/III/2004, S.G. Brayner-Barros \& P.R.F. Nascimento (PEUFR48290). Recife, Praia do Pina, 6/V/2005, S.G. Brayner-Barros \& H.A. Barros (PEUFR48291). Cabo de Santo Agostinho, Praia de Gaibú, 15/IX/2004, S.G. Brayner-Barros, S.M.B. Pereira \& M.E. BandeiraPedrosa (PEUFR48293).

Os exemplares ocorreram em substratos rochosos e/ou arenosos, como hospedeiro para Halimeda opuntia, Dictyota menstrualis, Dictyopteris delicatula, Bryothamniom triquetrum, Corallina sp., Gelidium sp.

12. Caulerpa verticillata J. Agardh, Till Alg. Syst. p. 6. 1872.

Fig. 27-28

Plantas com altura variando entre 0,5-(2,6)-3,0 cm. Estolão glabro, cilíndrico, ramificado, com 1,0 mm diâm. Rizóides ramificados. Ramos assimiladores constituídos por eixos principais, cilíndricos, ramificados, com diâmetro de 1,9 mm, e largura de 1,6 mm, distribuídos de maneira sobreposta. Os ramos verticilados se dividem, dicotômicamente, até cinco vezes, sem constricção nas dicotomias, ápices arredondados ou com um ou dois múcrons evidentes. Râmulos com diâmetro entre 0,5 e $0,9 \mathrm{~mm}$ (mais jovens) e 1,1 a 1,3 mm (mais velhos).

Material examinado: BRASIL. Pernambuco: Fernando de Noronha, Praia Buraco do Inferno, 25/IV/2006, D.C. Burgos (PEUFR48300). Fernando de Noronha, Praia Enseada do Cação, 25/IV/2006, D.C. Burgos (PEUFR48301). Fernando de Noronha, Laje Dois Irmãos, 27/IV/2006, D.C. Burgos (PEUFR48302). Fernando de Noronha, Praia da Biboca, 24/IV/2006, D.C. Burgos (PEUFR48303). Fernando de Noronha, Praia do Atalaia, 13/VI/2006, M.E. Bandeira-Pedrosa \& S.M.B. Pereira (PEUFR48304).

Os exemplares foram coletados, apenas, no Arquipélago de Fernando de Noronha (Tab. 2), na região entre marés e no infralitoral. Neste caso nas profundidades de 10,15 e $21 \mathrm{~m}$, sobre substrato rochoso. Alguns exemplares serviram de hospedeiros para Halimeda opuntia, Dictyopteris delicatula, Hypnea musciformis.
13. Caulerpa webbiana Montagne, Ann. Sci. Nat. Bot. v. 2 , n. 8 , p. 129.1837.

Fig. 29-30

Plantas com altura variando entre $0,5-(1,3)-1,5 \mathrm{~cm}$. Estolão glabro, cilíndrico, ramificado, com 1,0 mm diâm. Rizóides com pouca ramificação, lisos. Ramos assimiladores constituídos por eixos principais, cilíndricos, com diâmetro de $1,5 \mathrm{~mm}$, inicialmente desnudos e acima dispostos em pequenos râmulos sobrepostos, distribuídos em vários planos, com diâmetro $1,1 \mathrm{~mm}$, largura de 1,6 mm, divididos dicotomicamente e ápices ponteagudos.

Material examinado: BRASIL. Pernambuco: Fernando de Noronha, Praia do Boldró, 14/VI/2006, D.C. Burgos (PEUFR48305).

Os exemplares foram coletados sobre substrato rochoso na praia de Boldró (Fernando de Noronha) na profundidade de $15 \mathrm{~m}$ (Tab. 2).

\section{Discussão}

No presente trabalho o gênero Caulerpa está representado no litoral de Pernambuco e no Arquipélago de Fernando de Noronha por 13 espécies, quatro variedades e duas formas.

Em geral as espécies encontram-se bem distribuídas ao longo do litoral de Pernambuco. No entanto foi observado que Caulerpa kempfii e C. lanuginosa tiveram sua área de distribuição restrita ao litoral norte enquanto que $C$. serrulata só foi encontrada em uma praia do litoral sul (Praia de Serrambí). A maioria dos táxons, representado por cerca de $60 \%$ ocorreu tanto em substrato rochoso quanto arenoso, como observado por Oliveira-Carvalho et al. (2003). Com relação às praias, observou-se que em Ponta de Pedras, Pau Amarelo e Serrambí ocorreu uma maior diversidade de espécies.

Oliveira Filho (1977) referenciou para o Brasil 18 espécies, 13 variedades e sete formas. Atualmente, cerca de seis destes táxons são considerados sinônimos segundo Wynne (2005). No presente trabalho não foram encontrados C. ashmeadii Harvey, C. brachypus var. brasiliana Joly \& Semir, C. brachypus var. nordestina Joly \& Semir, C. cupressoides var. lycopodium f. elegans (P. Crouan \& H. Crouan) Weber Bosse, C. floridana W.R. Taylor, referidas por Oliveira Filho (1977) para a região de infralitoral. C. cupressoides var. lycopodium $\mathrm{f}$. mamillosa (Montagne) Weber Bosse, C. cupressoides var. serrata (Kützing) van Bosse, foram registradas pelo referido autor, respectivamente, para Ceará, Rio Grande do Norte, Espírito Santo e Ceará. C. cupressoides var. turneri van Bosse foi considerada como uma espécie rara para o litoral brasileiro, tendo sido encontrada apenas no litoral do Ceará. C. taxifolia (Vahl) C. Agardh foi 
citada pelo autor para Fernando de Noronha com base no trabalho de Murray (1891) e para o Espírito Santo. Pereira et al. (2002) referenciaram um total de 32 táxons para a costa pernambucana, não tendo sido encontrado neste trabalho a maioria dos táxons encontrados no infralitoral. Além disso, não foram consideradas algumas formas taxonômicas como C. mexicana f. pectinata, C. prolifera f. obovata, C. sertularioides f. brevipes e C. sertularioides f. longiseta. O número de representantes referidos para o Arquipélago de Fernando de Noronha foi bem inferior se comparado com Pereira et al. (2002) que analisaram 14 táxons. Igual comentário pode ser feito em relação ao trabalho de Villaça et al. (2006) que referiram 16 táxons. A baixa diversidade encontrada neste trabalho pode ser explicada pelo reduzido número de coletas realizadas no referido Arquipélago.

Uma das características do gênero Caulerpa é a morfologia plástica dos ramos eretos caracterizada, principalmente em algumas espécies, por modificações causadas em geral por mudanças ambientais (Oliveira
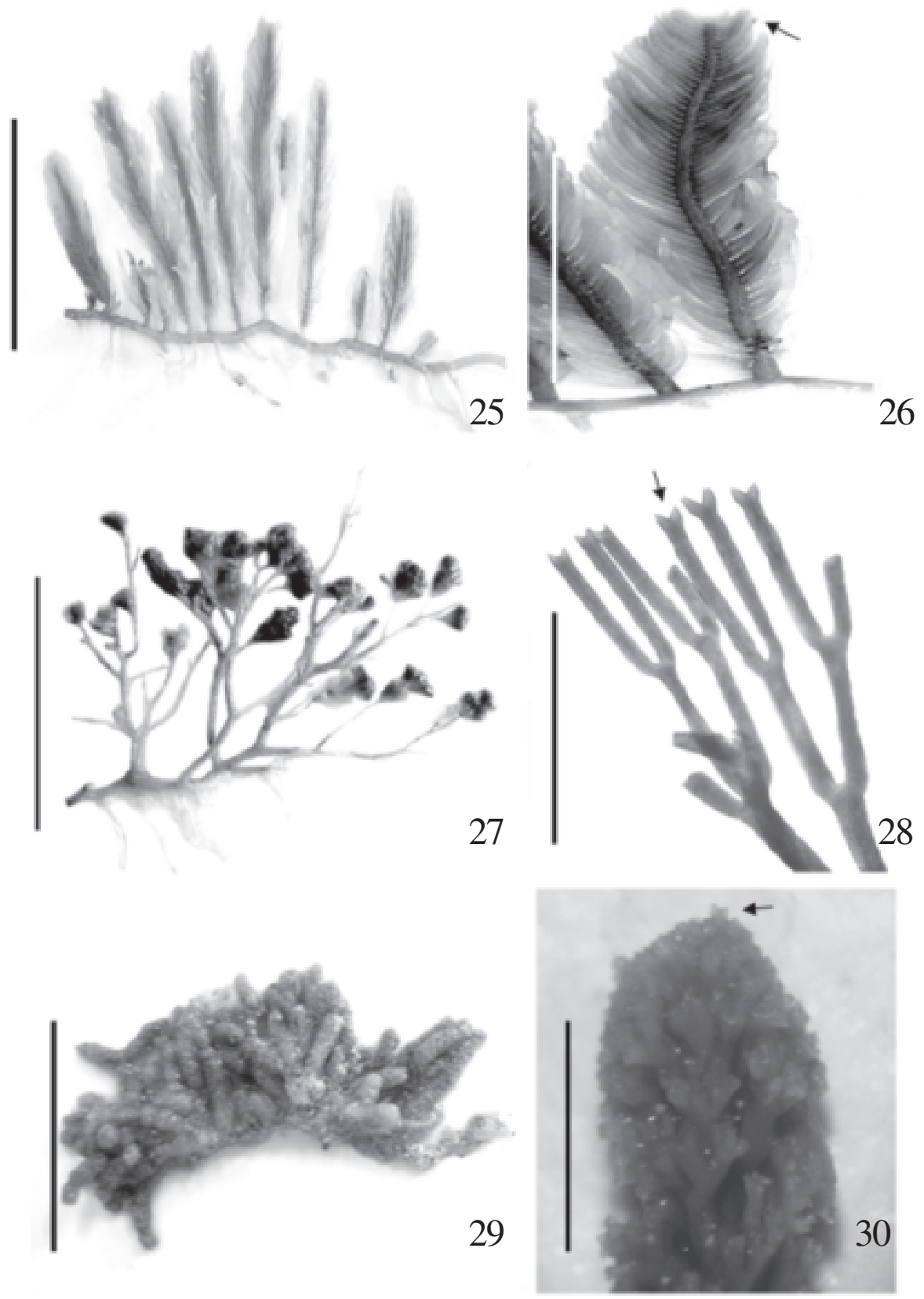

Figuras 25-26. Caulerpa sertularioides (S.G. Gmel.) M. Howe. 25. Aspecto geral da planta. 26. Detalhe do ramo assimilador lembrando uma "folha" pinada. Note detalhe do ápice mucronado (seta). 27-28. Caulerpa verticillata J. Agardh. 27. Aspecto geral da planta. 28. Detalhe do râmulo mostrando a presença de apenas dois múcrons (seta). 29-30. Caulerpa webbiana Montagne. 29. Aspecto geral da planta. 30. Detalhe dos filamentos sobrepostos e ápices ponteagudos. Observe detalhe do ápice (seta). Barras = $(25-27) 1 \mathrm{~cm} ;(28,30) 1 \mathrm{~mm}$. 
et al. 2005). Dentro deste contexto se encontra o "Complexo Caulerpa racemosa", nome este referido pela literatura e que corresponde às variedades racemosaoccidentalis-peltata (Verlaque et al. 2000). Atualmente a variedade peltata engloba a var. laetevirens, devido a testes desenvolvidos em cultivos no Japão, assinalando o acentuado polimorfismo desta espécie (Ohba \& Enomoto 1987; Wynne 2005). A variedade típica, var. racemosa apresenta-se semelhante as descritas pela literatura (Rehm \& Almodovar 1971; Modena et al. 2000; Durand et al. 2002; Ruilton et al. 2005; Raniello et al. 2006). C. racemosa var. occidentalis e C. racemosa var. peltata, a despeito da aparente semelhança, diferem na forma dos râmulos segundo Panayotidis \& Zuljevic (2001). Entretanto, foram coletados exemplares que possuíam caracteres pertencentes às duas variedades, sendo utilizado como critério para a identificação o maior número de râmulos por variedade; neste caso aconselha-se um estudo mais acurado utilizando análises moleculares.

Neste trabalho observou-se que representantes de Caulerpa sertularioides apresentavam características de diferentes formas taxonômicas num mesmo exemplar e por isto preferiu-se limitar a identificação em nível de espécie, seguindo Scrosati (2001) que reconheceu, apenas, em nível específico.

Pereira (1974) refere-se a Caulerpa cupressoides var. lycopodium f. disticha com râmulos em três ou quatro fileiras na base ou mesmo ao longo dos eixos eretos. Wynne (2005) cita C. cupressoides var. lycopodium f. tristicha como sinonímia de C. cupressoides var. lycopodium f. disticha com base em diversos trabalhos, confirmando Pereira (1974), que relatou a ocorrência de variedades e formas como aparentes gradações, sugerindo sinonímias. As plantas analisadas neste trabalho apresentaram as mesmas características.

Oliveira et al. (2005) referem-se a Caulerpa webbiana proveniente da Tanzânia, com a caracterização, formas dos ramos e diâmetros semelhantes aos encontrados em Pernambuco. As plantas identificadas como $C$. webbiana correspondem às descrições apresentadas por Oliveira et al. (2005) e De Clerck et al. (2005). Estes autores comentam que $C$. webbiana é morfologicamente semelhante a $C$. elongata Weber Bosse, diferindo desta por portar ramos assimiladores pseudodicotômicos e o estolão com râmulos curtos densamente dispostos. Esta espécie está presente na maioria das Ilhas Oceânicas do Brasil (Villaça et al. 2006), porém não se trata de material exclusivo de ilhas (Joly et al. 1969; Oliveira Filho 1974; Oliveira et al. 2005).

Considerando, apenas, a flora da região entre marés do litoral pernambucano observou-se que o gênero
Caulerpa apresenta uma grande diversidade taxonômica, pois, em torno de $75 \%$ dos táxons citados ocorre para o litoral brasileiro. Este fato se justifica porque a costa do referido Estado, se encontra inserida na Região Tropical, considerada uma das mais representativas em diversidade específica do litoral brasileiro (Horta et al. 2001).

\section{Agradecimentos}

À Coordenação de Aperfeiçoamento de Pessoal de Nível Superior (CAPES), pela bolsa concedida ao primeiro autor, e ao Conselho Nacional de Desenvolvimento Científico e Tecnológico (CNPq), pela bolsa de produtividade concedida ao segundo autor; ao PRONEX/FACEPE/CNPq, e ao Projeto UNIVERSAL $(\mathrm{CNPq})$, pelo apoio financeiro recebido para a realização das coletas.

\section{Referências bibliográficas}

Araújo, T.C.M.; Seoane, J.C.S. \& Coutinho, P.N. 2004. Geomorfologia da Plataforma Continental de Pernambuco. Pp. 39-57. In: E. Eskinazi-Leça, M.F. Costa \& S. Neumann-Leitão (orgs.). Oceanografia: um cenário tropical. Recife, Edições Bagaço.

Blackman, F.F. \& Tansley, A.G. 1902. A revision of the classification of the green algae. New Phycology 1: 17-24, 47-48, 89-96, 114-120, 133-144.

Coppejans, E. 1992. Marine Algae of Papua New Guinea (Madang Prov.) 2. A Revised and Completed List of Caulerpa (Chlorophyta - Caulerpales). Blumea 36: 383-410.

De Clerk, O.; Bolton, J.J.; Anderson, R.J. \& Coppejans, E. 2005. Guide to the Seaweeds of Kwazulu-Natal. Scripta Botanica Belgica 33: 1-294.

De Toni, G.B. 1889. Sylloge algarum omnium hucusque cognitarum. 1. (Sylloge Chlorophycearum) 1-12+i-cxxxix + $1-1315$.

Dumay, O.; Pergent, G.; Pergent-Martini, C. \& Amade, P. 2002. Variations in Caulerpenyne contents in Caulerpa taxifolia and Caulerpa racemosa. Journal of Chemical Ecology 28: 343-352.

Durand, C.; Manuel, M.; Boudouresque, C.F.; Meinesz, A.; Verlaque, M. \& Le Parco, Y. 2002. Molecular data suggest a hybrid origin for the invasive Caulerpa racemosa (Caulerpales, Chlorophyta) in the Mediterranean Sea. Journal Evolue Biology 15: 122-133.

Feldmann, J. 1946. Sur L' heteroplastis de certaines Siphonales et leur classification. Academy Science 222: 752-753.

Forsskaal, P. 1775. Flora Aegyptiaca-Arabica sive descriptiones Plantarum. Hauniae.

Graham, L.E. \& Wilcox, L.W. 2000. Algae. Prentice Hall.

Greville, R.K. 1830. Algae Britannicae. Edinburgh.

Harvey, W.H. 1858. Nereis Boreali-Americana. Smithsonian Contributions to Knowledge 5: 1-258.

Horta, P.A.; Amancio, E.; Coimbra, C.S \& Oliveira, E.C. 2001. Considerações sobre a distribuição e origem da flora de macroalgas marinhas brasileiras. Hoehnea 28: 243-265.

Joly, A.B.; Oliveira Filho, E.C. \& Narchi, W. 1969. Projeto de criação de um parque nacional marinho na região de Abrolhos, Bahia. Anais Academia Brasileira Ciências 41: 247-251.

Kützing, F.T. 1843. Phycologia generalis oder Anatomie, Physiologie und Systemkundeder Tange. Leipzig.

Lamouroux, J.V. 1809. Memoire sur les Caulerpes. Journal of Botany 2: 136-146. 
Macedo, S.J.; Muniz, K. \& Montes, M.J.F. 2004. Hidrologia da região costeira e Plataforma continental do estado de Pernambuco. Pp.255-286. In: E. Eskinazi-Leça; S. Neumann-Leitão \& M.F. da Costa (orgs.). Oceanografia: um cenário tropical. Recife, Editora Bagaço.

Meñez, E.G. \& Calumpong, H.P. 1982. The Genus Caulerpa from Central Visayas, Philippines. Smithsonian Contributions To The Marine Sciences 17: 1-20.

Modena, M.; Matricardi, G.; Vacchi, M. \& Guidetti, P. 2000. Spreading of Caulerpa racemosa (Forsskaal) J. Agardh (Bryopsidaceae, Chlorophyta) along the coasts of the Ligurian Sea. Cryptogamie Algologie 21: 301-304.

Muñoz, A.O.M. \& Pereira, S.M.B. 1997. Caracterização qualiquantitativa das comunidades de macroalgas nas formações recifais da Praia do Cupe. Pernambuco (Brasil). Trabalhos Oceanográficos Universidade Federal de Pernambuco 25: 93-109.

Murray, G. 1891. Algae in H.N. Riddley: Notes on the botany of Fernando de Noronha. Journal Linnean Society Botany 27: 75-80.

Ohba, H. \& Enomoto, S. 1987. Culture studies on Caulerpa (Caulerpales, Chlorophyceae) II. Morphological variation of C. racemosa var. laetevirens under various culture conditions. Japanese Journal Phycology 35: 178-188.

Oliveira-Carvalho, M.F.; Pereira, S.M.B. \& Zickel, C.S. 2003. Florística e distribuição espaço-temporal das clorofíceas bentônicas em trechos recifais do litoral norte do estado de Pernambuco - Brasil. Hoehnea 30: 201-212.

Oliveira, E.C.; Österlund, K. \& Mtolera, M.S.P. 2005. Marine plants of Tanzania. A field guide to the seaweeds and seagrasses. Stockholm, Stockholm University.

Oliveira Filho, E.C. 1974. Am annotated list of the Brasilian seaweeds in Dickie's herbarium. Journal Linnean Society Botany 69: 229-238.

Oliveira Filho, E.C. 1977. Algas marinhas bentônicas do Brasil. Tese (Livre-Docência), São Paulo, Universidade de São Paulo.

Panayotidis, P. \& Zuljevic, A. 2001. Sexual reproduction of invasive green alga Caulerpa racemosa var. occidentalis in Mediterranean Sea. Oceanology Acta 24: 199-203.

Papenfuss, G.F. 1955. Classification of the algae. Pp. 115-224. In: R.C. Miller; E.L. Kessel \& G.F. Papenfuss (eds.). A century of progress in the natural sciences, 1853-1953. San Francisco, California Academy of Sciences.
Pereira, S.M.B. 1974. Cloroficeas da Ilha de Itamaracá e arredores (Estado de Pernambuco-Brasil). Dissertação (Mestrado em Botânica). São Paulo, Universidade de São Paulo.

Pereira, S.M.B.; Oliveira-Carvalho, M.F.; Angeiras, J.A.P.; BandeiraPedrosa, M.E.; Oliveira, N.M.B.; Torres, J.; Gestinari, L.M.; Cocentino, A.L.M.; Santos, M.D.; Nascimento, P.R.F. \& Cavalcanti, D.R. 2002. Algas bentônicas do Estado de Pernambuco. Pp. 97-124. In: M. Tabarelli \& J.M.C. Silva (eds.). Diagnóstico da biodiversidade de Pernambuco. Recife, Editora Massangana.

Rainiello, R.; Lorenti, M. \& Buia M.C. 2006. Photocclimation of the invasive alga Caulerpa racemosa var. cylindracea to depth and daylight patterns and a putative new role for siphonaxanthin. Marine Ecology 27: 20-30.

Rehm, A.E. \& Almodovar, R. 1971. The zonation of Caulerpa racemosa (Forsskaal) J. Agardh at La Parguerra, Puerto Rico. Revue Algologique 2: 144 - 151.

Ruiltton S.; Verlaque, M. \& Boudouresque, C.F. 2005. Seasonal changes of the Caulerpa racemosa var. cylindracea (Caulerpales, Chlorophyta) at the northwest limit of its Mediterranean range. Aquatic Botany 82: 55-70.

Scrosati, R. 2001. Population dynamics of Caulerpa sertularioides (Chlorophyta: Bryopsidales) from Baja California, Mexico, during El Niño and La Niña years. Journal of Marine Biology Association 81: 721-726.

Smith, G.M. 1955. Cryptogamic Botany. I. Algae and Fungi. New York, Mcgraw-Hill.

Taylor, W.R. 1960. Marine algae of the eastern tropical and subtropical coast of the Americas. Michigan, The University of Michigan Press.

Verlaque, M.; Boudouresque, C.F. \& Gravez, V. 2000. The Caulerpa racemosa complex (Caulerpales, Ulvophyceae) in the Mediterranean Sea. Botany Marine 43: 49-68.

Villaça, R.; Pedrini, A.G.; Pereira, S.M.B. \& Figueiredo, M.A.O. 2006. Flora marinha bentônica das Ilhas Oceânicas brasileiras. Pp. 106-146. In: R.J.V. Alves \& J.W.A. Castro (orgs.). Ilhas Oceânicas brasileiras da pesquisa ao manejo. Brasília, Ministério do Meio Ambiente/ Sociedade Brasileira de Ficologia.

Wynne, M.J. 2005. A checklist of benthic marine algae of the tropical and subtropical western Atlantic: second revision. Nova Hedwigia 116: 72 . 